\title{
The Action Result of the Concentrated Load on the Briquetteswhich Obtained from the Technogenous Material
}

\author{
Yu. N. Loginov', N. A. Babailov², and D. N. Pervukhina ${ }^{1}$ \\ ${ }^{1}$ Ural Federal University named after the first President of Russia B.N.Yeltsin, 19 Mira st., \\ Ekaterinburg, 620002, Russia \\ ${ }^{2}$ Institute of Engineering Science, Ural Branch of the Russian Academy of Sciences, 34 \\ Komsomolskaya st., Ekaterinburg, 620049, Russia
}

\section{Abstract}

In this study, the calculation results of the briquette stress state by the Finite element method are presented. The fields of compressive and tensile stresses in briquette are determined. The conditions affecting the process of the briquette destruction are considered.

Keywords: metallurgical briquette, finite element method, stress state

Corresponding Author: Yu. N.

Loginov; email:

j.n.loginov@urfu.ru

Received: 6 June 2017

Accepted: 9 July 2017

Published: 24 August 2017

Publishing services provided by Knowledge E

(c) Yu. N. Loginov et al. This article is distributed under the terms of the Creative

commons Attribution

License, which permits unrestricted use and redistribution provided that the original author and source are credited.

Selection and Selection and Peer-review under the responsibility of the Technogen Conference Committee.

\section{G OPEN ACCESS}

\section{Introduction}

The raw materials for a metallurgical remelting are often finely dispersed phase. This is either the natural state of minerals or the grinding in the operations of enrichment, as well as the wastes of the chemical or metallurgical industry (sludge, dust, etc $[1,2]$ ). If the subsequent processing will associated with the pyrometallurgical production, it is prevented the removal of fine particles by the convective flow of the ascending gases. Therefore, such raw material must be enlarge, which is achieved by various methods, including the briquetting processes [3]. Economic problems of briquetting were discussed in the article [4] and the problems of processes simulation are described in the publication [5].

In the plunger or the roll briquetting [6], the briquettes of various shapes are obtained. The current problem is to choose the shape of the briquette, in which the least loss of the material mass occurs during transport and handling operations.

\section{Result and Discussion}

During the briquette formation, the stress state is usually analyzed when a distributed load is applied to the contact area of the briquette. The briquettes are destroyed during 


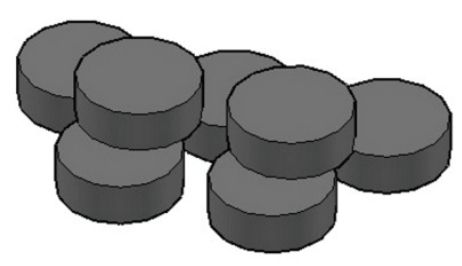

a

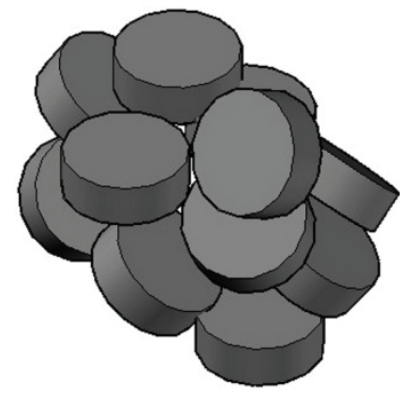

$\mathrm{b}$

Figure 1: Ordered (a) and chaotic (b) the briquettes arrangement during the transport operations.

transport operations due to the impact of the briquette edges to each other. Fig. 1 shows the possible orderly and chaotic arrangement of briquettes during transport operations. As a rule, briquettes have relatively small size, so it takes large investment of time to organize their arrangement. So a chaotic arrangement of the briquettes is preferred.

Consequently, the point loads appear in places of mutual contact. The influence of even a small force in the place of point contact causes infinitely high stresses. These stresses lead to the destruction of the briquette material. The crumble of the once briquetted raw materials again leads to the additional costs for the utilization of the crumbling material. The calculation of the stress state should allow to solve the problem of finding the optimal shape of the briquette.

The stress state of the simplest form briquette obtained by plunger briquetting is determined in this article. Against the background of a more productive roll briquetting process, the plunger pressing differs in that it is not possible to fulfill the capture conditions characterized the roll briquetting $[7,8]$. To simulate the capture of the briquette material, the finite element method implemented in the ABAQUS program module is applied.

The following statement of the problem is applied. The diameter of the briquette is $100 \mathrm{~mm}$ and its height is $50 \mathrm{~mm}$. The briquette is loaded by a concentrated force that is specified in projections on the longitudinal axis $z(1000 \mathrm{~N})$ and on the radial axis $\mathrm{r}$ $(1000 \mathrm{~N})$. So the resultant force equals $100 * 2=1410 \mathrm{~N}$ and it is directed at an angle of $45^{\circ}$ about the briquette axis.

As can see in Fig. 3a, the redistribution of equivalent stresses occurs with attenuation as the distance from the point of force application is removed. The maximum value of the equivalent stress is 15.5 MPa. This allows comparing it with the maximum allowable value of stress for the briquette material. The Mises stresses show a stressed state 


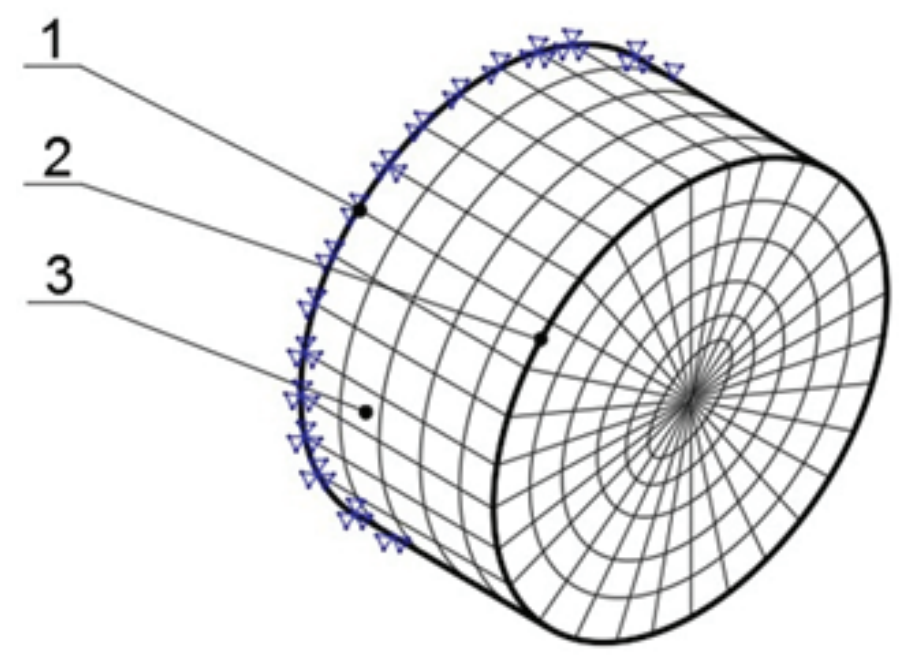

Figure 2: The briquette shape and boundary conditions for the problem solution (where 1 is the boundary condition in the form of fixation; 2 is the point of force application in the cylinder edge; 3 is the briquette).

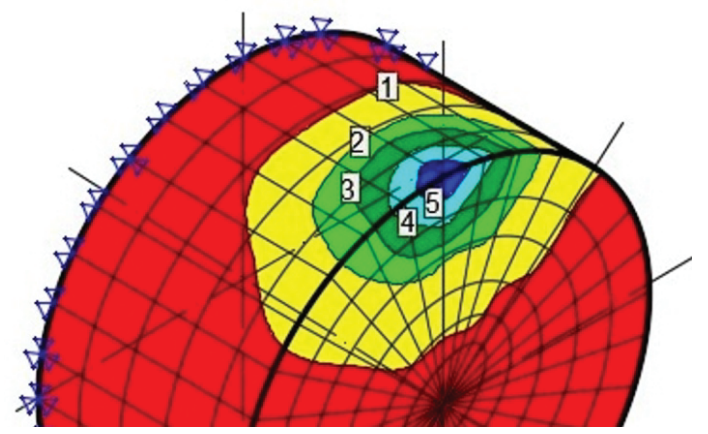

a

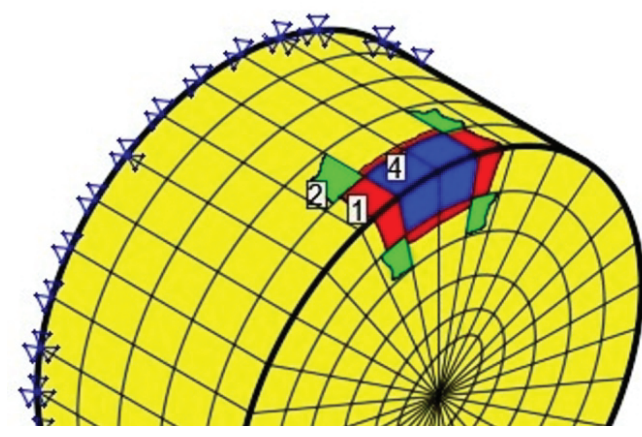

$\mathrm{b}$

Figure 3: The briquette distribution of the equivalent von Mises stress (a): where 1-26.6 MPa; $2-52.3 \mathrm{MPa}$; 3-78.0 MPa; 4-10.4 MPa; 5-12.9 MPa and the pressure (b): where 1- -1.79 MPa; 2-0.77 MPa; 3-3.32 $\mathrm{MPa} ; 4-5.87 \mathrm{MPa}$.

without regard for the sign, which does not allow adequately assessing the possibility of the briquette destruction.

At first sight, the effect of the compressive force on the briquette edge should leads to the creation of compression stresses. However, the pressure distribution shown in Fig. $3 b$ shows that this value in the neighboring regions has different signs.

In Fig. 3 the results in the form of the equal level areas of the distribution of equivalent von Mises stresses are presented.

In the area of a force application, the pressure is positive, but in a series of finite elements it changes sign to negative. The magnitude of the pressure can be correlated with the index of the stress state, but the signs will have to be reversed. This is more clearly illustrated in Fig. 4, which shows the distribution of the principal maximum and minimum stresses in the briquette. 


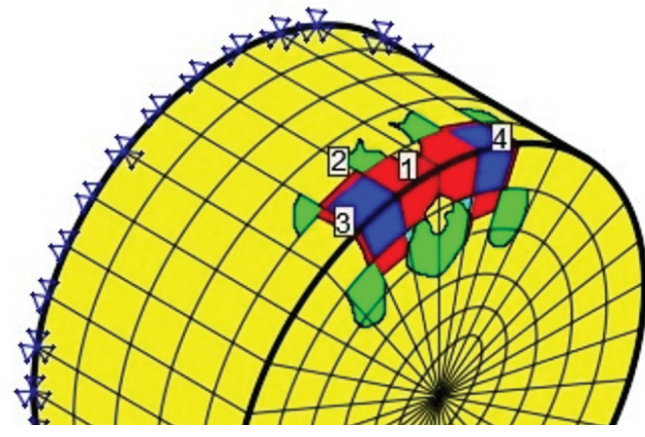

a

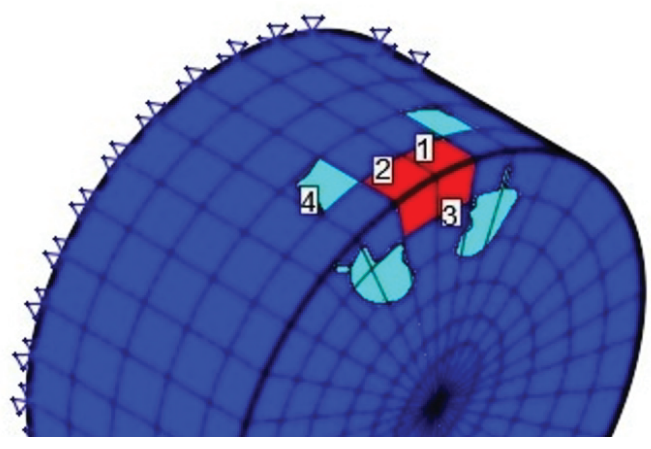

b

Figure 4: Fig. 4. The briquette distribution of the principal maximum stress (a): 1- -0.17 MPa; $2-2.36 \mathrm{MPa}$; 3-4.89 MPa; 4 7.42 MPa and minimum stress (b): 1- -14.8 MPa; 2 - -10.9 MPa; 3 - -7.01 MPa; 4 - -3.13 MPa.

Here is, the sign rule corresponds to the one adopted for the displaying of the stress state factor. It can be seen that the regions of a negative values for these two stresses coincide, and the range of stresses with a positive sign exists, which characterizes the tension condition. The presence of tensile stress creates the prerequisites for the destruction of the briquette and the crumbling of its edges.

An additional factor affecting the destruction process is the creation of gas pressure inside the briquette during its deformation. Therefore, the preconditions must be created for the gas throttling processes to take place and for removing internal pressure. Another factor that should be taken into account in practice it is the uneven the density distribution, respectively, and strength in the briquette itself.

\section{Summary}

The reason for the crumble edges of metallurgical briquettes is a complex stress state in the areas of interaction of the adjacent briquettes. The calculations revealed the presence of adjacent areas to the action of the compressive and tensile stresses. These stresses create the conditions for the briquette destruction during transport operations. The smallest crumbling has the briquette with the rounded side edges. This is typical for briquettes obtained with roll briquetting.

\section{References}

[1] I. F. Kurunov, "Environmental aspects of industrial technologies for recycling sludge and dust that contain iron and zinc," Metallurgist, vol. 55, no. 9-10, pp. 634-639, 2012. 
[2] I. L. Gonik, V. P. Lemyakin, and N. A. Novitskii, "Features of the use of briquetted iron-bearing wastes," Metallurgist, vol. 55, no. 5-6, pp. 397-400, 2011.

[3] N. A. El-Hussiny and M. E. H. Shalabi, "A self-reduced intermediate product from iron and steel plants waste materials using a briquetting process," Powder Technology, vol. 205, no. 1-3, pp. 217-223, 2011.

[4] P. Pustějovská, S. Brožová, and S. Jursová, "Possibilities of economic utilization of briquetted metallurgical waste," in Proceedings of the 23rd International Conference on Metallurgy and Materials, METAL 2014, pp. 1841-1845, Czech Republic, May 2014.

[5] M. Wang, S. C. Wang, J. Y. Duan, and P. C. Zhang, "Study of the modeling and simulation for waste briquetting machine based on the compression/pushing mechanical hydraulic system," Advanced Materials Research, vol. 912-914, pp. 790794, 2014.

[6] R. T. Dec and A. Zavaliangos, "Powder processing in the roller Press - Theory and practice," Powder Handling and Processing, vol. 19, no. 1, pp. 23-28, 2007.

[7] Y. N. Loginov, S. P. Bourkine, and N. A. Babailov, "Cinematics and volume deformations during roll-press briquetting," Journal of Materials Processing Technology, vol. 118, no. 1-3, pp. 151-157, 2001.

[8] Y. N. Loginov, N. A. Babailov, and S. P. Burkin, "Bulk deformation in roller briquetting of metallurgical waste," Russian Metallurgy (Metally), no. 1, pp. 53-58, 2000. 